\title{
VitiMeteo and Agrometeo: Two platforms for plant protection management based on an international collaboration
}

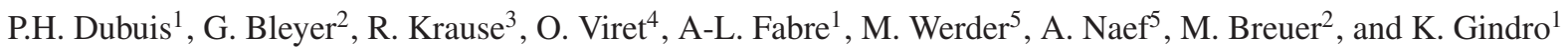 \\ ${ }^{1}$ Agroscope, Plant Protection, Mycology and Biotechnology, route de Duillier 50, 1260 Nyon, Switzerland \\ ${ }^{2}$ WBI, Staatliches Weinbauinstitut Freiburg, Merzhauserstrasse 119, 79100 Freiburg, Germany \\ ${ }^{3}$ Geosens GmbH, Gewerbestrasse 14, 79227 Schallstadt, Germany \\ ${ }^{4}$ General Direction of Agriculture, Viticulture and Veterinary Affairs, av. De Marcelin 29, 1110 Morges, Switzerland \\ ${ }^{5}$ Agroscope, Plants and Plant Products, Fruit-Production Extension, Müller-Thurgaustr. 29, 8820 Wädenswil, Switzerland
}

\begin{abstract}
The negative effects of plant protection products on the human health and the environment have become a major concern for consumers and politics in Europe. In the last years new policies for risk mitigation and reduction of use of synthetic pesticides has been enforce in Europe and Switzerland. A possible strategy to reduce the use of plant protection products is to spray according to the epidemic of diseases and pests by following decision support systems (DSS). The platform VitiMeteo offers a wide set of forecasting models for viticulture including downy and powdery mildew, black rot, grape berry moth and rust mite. Two research institutes the Staatliches Weinbauinstitut Freiburg (Germany) and Agroscope (Switzerland) developed VitiMeteo jointly. A consortium was built with the company Geosens (Germany) which is in charge of the programming of the different forecasting software. Each institute is running his own internet website with specific tools and feature for each country but the core of the system is the same. The combination of these different DSS allows a significant reduction of plant protection products used. All these forecasting systems and tools are freely available for the winegrowers on the platform www.vitimeteo.de and www.agrometeo.ch. The use of these platforms helps the winegrowers to meet current society's expectations.
\end{abstract}

\section{Introduction}

The vast majority of the vineyards for wine production worldwide is planted with Vitis vinifera cultivars all sensitive to several fungal diseases such as Plasmopara viticola, Erysiphe necator, Botrytis cinerea and Guignardia bidwellii. Preventive applications of plant protection products are essential in order to produce high quality grapes at the desired yield. In Switzerland and Germany, typically 7 to 12 applications over the growing season are requested in order to achieve a good protection. In practice, winegrowers spray fungicides from short after budburst (3-4 leaves) until beginning of véraison at regular intervals. To define the intervals they consider weather forecast but only to a lesser extend disease pressure. In Switzerland and Germany, mating disruption is widely used to control grape berry moths and the use of insecticides is consequently very limited. Predatory mites (e.g. Typhlodromus pyri and Amblyseius andersoni) control mites such as Tetranychus urticae and Panonychus ulmi.

Integrated Pest Management (IPM) is the standard in Switzerland and Germany since the 90 s and has led to a more focused and limited use of plant protection products. Despite this fact, the use of so-called pesticides has become a social and political issue. The possible negative effects of plant protection products on human health and environment are widely discussed. National Action Plans have been enforced in Germany and Switzerland with the goal to reduce these risks and find sustainable alternatives.
There are different ways to limit the use of plant protection products. Elicitors that stimulate the natural defence mechanisms of vine have been developed but they do not reach the level of performance of standard fungicides and must be used in combination with other products. Alternative natural products also usually have a limited efficacy and must be integrated in specific strategies. An important possible progress for a reduction of the use of plant protection products is an accurate simulation of the epidemiological development of fungi and pests by forecasting models that enable spraying according to the infection risks. The most radical alternative to reduce drastically the use of plant protection products is the planting of resistant varieties. There are breeding programs in several countries and new resistant varieties with interesting organoleptic and agronomic characteristics are emerging. Winegrowers are very interested to try them but there are some regulation issues especially with AOC wines in traditional winegrowing regions.

\section{VitiMeteo models and platforms}

\subsection{Weather station net}

In Switzerland, a national network of over 170 weather stations located mainly in vineyards and fruit orchards was established in order to have local microclimatic weather data measured directly in the field. Such a countrywide weather station network also exists in Germany. The weather stations record temperature $\left({ }^{\circ} \mathrm{C}\right)$, rainfall $(\mathrm{mm})$, 
relative humidity (\%) and leaf wetness duration (h) in 10 minutes intervals. All data are transferred in real time to a central database and then available for the different models.

\subsection{VitiMeteo models}

Since the early 2000s, the two research institutes, the Staatliches Weinbauinstitut Freiburg (Germany) and Agroscope (Switzerland) in collaboration with the company Geosens have formed an international consortium that has developed the different VitiMeteo models. Currently the VitiMeteo consortium produced models for diseases (Plasmopara viticola, Erysiphe necator and Guignardia bidwellii), for insects (grape berry moths, Hyalesthes obsoletus), for mites (Calepitimerus vitis) and for the vine development (growth and phenology). The scientific knowledge integrated in the models comes from own experimental results, from the literature and from other scientists willing to collaborate and share their experimental data with the VitiMeteo group. This international collaboration made it possible to create new open decision support systems.

VitiMeteo-Plasmopara and VitiMeteo-BlackRot are both mechanistic models based on the biological development of Plasmopara [1-3] and Guignardia bidwellii [4] respectively. VitiMeteo-Oidium is a statistical model that indicates an infection risk and enable the grower to adapt the spray intervals according to the risk, and to the last fungicide applied $[5,6]$.

Summarized and detailed tables as well as graphs present the results with increasing complexity. The experts in charge of the models have the possibility to adjust most of the parameters to their own observations and there are no black boxes. This help to understand the model outputs and explain failures in control strategies.

The growth model after Schultz [7] indicates the number of developed main leaves and the leaf surface per main shoot. This parameter gives useful information from the newly unfolded and unprotected leaves since the last treatment. VitiMeteo-Phenology, a phenology model after Molitor [8] simulates the phenological development of three selected cultivars: Riesling, Müller-Thurgau and Pinot noir [9].

\subsection{Platforms and website}

Each institute is running an own internet website with specific tools and features for each country but the core of both platforms is the same. In Germany the website ww. vitimeteo. de is dedicated exclusively to grapevine and a specific monitoring tool gather field observations allover Baden-Württemberg giving an overview of the actual situation of diseases and pests. The VitiMeteo-Plasmopara, VitiMeteo-Oidium and VitiMeteo-BlackRot models are also run on the agricultural meteorology websites of Rhineland-Palatinate and Bavaria. In Switzerland, the website www.agrometeo.ch covers a broader set of crops including grapevine, fruit orchards and field crop. Agrometeo also present a calculation module to adapt the product dosage to the leaf volume both for vineyard and for orchards. Both research institute developed control strategies based on model outputs. These strategies have been validated by field trials in different climatic conditions over the years. All these data and tools are available free of charge for the growers and represent an excellent source of information for them to manage plant protection. Geosens also offers a forecasting service www.vitimeteo.info. Growers can send their own weather data and Geosens will run the selected models and gives them the results in a dedicated website.

\section{Validation and practical use}

The different models were validated by observations in an external laboratory and in fields as well as in field trials. The different parameters were adjusted according to these observations. For example, Downy mildew oospore maturation is determined by selecting leaf pieces of approximatively $5 \mathrm{~mm}^{2}$ that are stored in Falcon tubes with open caps placed outside. At regular interval in spring, a few leaf pieces are transferred to Petri dishes and incubated at $100 \% \mathrm{RH}$ and $20^{\circ} \mathrm{C}$. Oospores are considered mature when they are able to germinate within $24 \mathrm{~h}$ under these conditions. In order to validate the VitiMeteo-Plasmopara model an observation laboratory under field conditions was set up in Changins (Switzerland). It consists in rows of sensitive cultivars of 12 vines of Pinot noir, Gamay and Chasselas. In autumn infected Downy mildew, leaves are deposited on the soil beneath the vines to get a strong inoculum. First oilspots and epidemic kinetic are monitored as well as powdery mildew development.

Expert software generally permits to modify important model parameters and this possible parametrisation proved to be a major advantage in the model development as it allows continuous optimisation.

\subsection{VitiMeteo-Plasmopara}

The growers need to decide when they have to make the first fungicide spray to control downy mildew. For this key issue different strategies are possible but they all rely on the knowledge of when the primary infection occurs. Models can give the growers this information. The comparison of the predicted primary infection and its incubation period with the first observed symptoms in the field laboratory over a period of 16-years shows the performance of the VitiMeteoPlasmopara model (Table 1). For 10 years (62.5\%), the model calculated correctly the date of the primary infection, for three years $(18.75 \%)$ it calculated a too early date and for three years $(18.75 \%)$ a date too late. This demonstrates that the model is accurate and can serve as decision support to determine the timing of the first spray. The weather conditions in the field laboratory are somewhat different from those in the nearby field where the weather station is standing and particularly the temperature is slightly higher. This fact can explain partly why in some years the primary infection predictions based on weather data from the field where sometimes too late.

\subsection{VitiMeteo-Oidium}

Decision support systems are a key element for reducing the number of sprays. Indeed spraying according to the disease risk and epidemic make it possible to adapt the timing of the first spray and the following intervals 
Table 1. Validation of downy mildew model VitiMeteo-Plasmopara by comparing predicted primary infections and observed first oilspots in the field laboratory in Changins $(\mathrm{CH})$ from 2003 until 2018.

\begin{tabular}{|l|c|c|c|l|}
\hline Year & $\begin{array}{c}\text { VM-Plasmo. } \\
\text { Predicted } \\
\text { primary } \\
\text { infection }\end{array}$ & $\begin{array}{c}\text { VM-Plasmo. } \\
\text { alculated end } \\
\text { of incubation }\end{array}$ & $\begin{array}{c}\text { First oilspots } \\
\text { observed in field } \\
\text { laboratory }\end{array}$ & $\begin{array}{l}\text { Diff. } \\
\text { [day] }\end{array}$ \\
\hline 2003 & 11.5 & 23.5 & 26.5 & +3 \\
\hline 2004 & 1.6 & 9.6 & 11.6 & +2 \\
\hline 2005 & 14.5 & 24.5 & 6.6 & +12 \\
\hline 2006 & 8.5 & 19.5 & 22.5 & +3 \\
\hline 2007 & 30.4 & 10.5 & 29.5 & +19 \\
\hline 2008 & 16.5 & 25.5 & 26.5 & +1 \\
\hline 2009 & 27.5 & 2.6 & 25.5 & -8 \\
\hline 2010 & 5.5 & 20.5 & 18.5 & -2 \\
\hline 2011 & 11.5 & 19.5 & 16.5 & -3 \\
\hline 2012 & 2.5 & 11.5 & 10.5 & -1 \\
\hline 2013 & 15.5 & 2.6 & 17.5 & -16 \\
\hline 2014 & 27.4 & 9.5 & 5.5 & -4 \\
\hline 2015 & 3.5 & 11.5 & 11.5 & 0 \\
\hline 2016 & 11.5 & 23.5 & 9.5 & -14 \\
\hline 2017 & 7.5 & 18.5 & 23.5 & +5 \\
\hline 2018 & 9.5 & 20.5 & 29.5 & +9 \\
\hline
\end{tabular}

Table 2. Summary of nine field trials showing the disease pressure, the number of sprays and the reduction of number of spray achieved by using VitiMeteo-Oidium. Disease pressure: $0=$ low; $+=$ medium; $++=$ high.

\begin{tabular}{|l|c|c|c|l|}
\hline $\begin{array}{l}\text { Location } \\
\text { and } \\
\text { year }\end{array}$ & $\begin{array}{c}\text { Disease } \\
\text { pressure }\end{array}$ & $\begin{array}{c}\text { Number of } \\
\text { spray in } \\
\text { reference }\end{array}$ & $\begin{array}{l}\text { Number of } \\
\text { spray with } \\
\text { VM-Oidiu }\end{array}$ & $\begin{array}{l}\text { Reduction } \\
\text { number and } \\
\text { and percent }\end{array}$ \\
\hline Chalais 2010 & + & 6 & 5 & $1(16.7 \%)$ \\
\hline Chalais 2011 & 0 & 6 & 6 & $0(0 \%)$ \\
\hline Chalais 2013 & ++ & 7 & 6 & $1(14.3 \%)$ \\
\hline Leytron 2009 & 0 & 6 & 4 & $2(33.3 \%)$ \\
\hline Leytron 2010 & 0 & 6 & 5 & $1(16.7 \%)$ \\
\hline Leytron 2014 & ++ & 8 & 7 & $1(12.5 \%)$ \\
\hline Perroy 2010 & 0 & 7 & 7 & $0(0 \%)$ \\
\hline Pully 2012 & ++ & 8 & 7 & $1(12.5 \%)$ \\
\hline Changins 2014 & ++ & 8 & 6 & $2(25 \%)$ \\
\hline Average & & $\mathbf{6 . 9}$ & $\mathbf{5 . 9}$ & $\mathbf{1 ( 1 4 . 6 \% )}$ \\
\hline
\end{tabular}

generally leading to fewer treatments. Validation of the powdery mildew model in nine field trials between 2009 and 2014 by comparing standard spraying schedule to spraying according to the VitiMeteo-Oidium model associated strategy demonstrates an average reduction of one spray per season corresponding to a $14.6 \%$ reduction (Table 2). The performance of the two spray schedules was similar and no reduction in disease control was observed when using VitiMeteo-Oidium [6].

\subsection{Crop adapted spraying}

Grapevine develops a large canopy within a relative short period and its leaf surface is increasing very rapidly until the first trimming. This characteristic is important and has two main consequences. First, the spray intervals have to be adapted to the growth to protect new unsprayed leaves appearing after the last treatment especially with contact fungicides. During this fast growth phase, the spray intervals have to be reduced. The growth model according to Schultze [7] calculates this development. The Weinbauinstitut of Freiburg im Breisgau has developed a successful strategy based on this growth model in which spray intervals are determined by a fixed vine growing value. Secondly, the quantity of fungicide to be sprayed can be adapted to the leaf surface in order to deposit a constant quantity of active ingredient per $\mathrm{cm}^{2}$ of leaf surface during the entire growth season. A simple way to estimate the leaf surface under practical conditions is to measure the leaf canopy volume called vine wall 
volume. The product dosage can be adapted according to this measured volume in order to achieve a constant deposit [10]). The easy to use calculation module available on www.agrometeo.ch makes it possible to reduce the fungicide quantity sprayed by $20 \%$ in average over a season without any performance reduction [11].

\subsection{Meetings and knowledge transfer}

Internal meetings, seminars for users and knowledge transfer are key factors for the success of VitiMeteo. The practical and scientific experiences with the models at the different locations are discussed during annual meetings. If necessary and relevant, new results are implemented into the models. Parallel to internal meetings, training seminars were organized for the users of the system, such as advisers or winegrowers. The users learn the practical application of the VitiMeteo-tools and benefit from the models. Many lectures and publications in the recent years supplemented the knowledge transfer into practice.

\section{Conclusions and perspectives}

The diseases and pests forecasting models based on microclimatic weather data are essential sources of information for the winegrowers to manage optimally their plant protection strategies. Another indispensable source of information is the monitoring of the vineyard for the presence of symptoms. Growers need to integrate all these information in strategies and translate them into actions. The VitiMeteo models and the internet platforms www.vitimeteo.de, www.vitimeteo.info and www.agrometeo.ch gives them important information and strategies adapted to the local conditions. These platforms are widely used by growers and advisors. VitiMeteo models and especially VitiMeteo-Plasmopara is available all over Germany and Switzerland as well as for some regions of Austria, Northern Italy, Czech Republic and France covering more than 200'000 ha of vineyards.

The philosophy of the VitiMeteo consortium is that these platforms have to be modular, flexible and agile. They have to match with the grower's needs, deliver useful information and work accurately on a daily basis (robustness). In order to reach these goals continues scientific and technical improvement and development is necessary. As the research institutes own the algorithms, new pertinent scientific knowledge can easily be introduced into the models. Collaboration with other scientists has enabled to develop a broad set of models and tools. This open-minded collaboration form an important part of the success of this project as well as the synergies between the different research institutes.
The combination of different diseases and pests forecasting models make it possible to reduce the number of sprays. The reduction depends on the disease epidemic and the weather conditions but can range from 0 to $30 \%$. Furthermore, the combination of the models with the crop adapted spraying method make it possible to reach the overall goals of National action plans in Switzerland and Germany set to reduce the use of plant protection products and guaranteeing the production of high quality grapes and covering the three pillars of sustainability: ecology, economy and social.

Thanks for scientific contributions to the models:

Prof. D. Molitor, Luxembourg Institute of Science and Technology (LIST), specifically for the black rot model and the phenology model.

Prof. H.R. Schultz, Hochschule Geisenheim University (Germany), specifically for the growth model.

Dr. W.K. Kast of the State Institute for Viticulture, Oenology and Fruit Technology, Weinsberg, (Germany) specifically for the powdery mildew risk model.

Dr. M. Maixner from Julius Kühn-Institute (JKI), Federal Research Centre for Cultivated Plants (Germany), specifically for the bois noir model.

\section{References}

[1] O. Viret, B. Bloesch, A.-L. Fabre, W. Siegfried, G. Bleyer; B. Hubert, H.-H. Kassemeyer, V. Steinmetz, Revue Suisse Viti. Arbo. Hortic. 37, 65 (2005)

[2] G. Bleyer, H.-H. Kassemeyer, O. Viret, W. Siegfried, R. Krause, OIBC wprs Bull. 36, 35 (2008)

[3] P.-H. Dubuis, O. Viret, B. Bloesch, A.-L. Fabre, A. Naef, G. Bleyer, H.-H. Kassemeyer, R. Krause, Revue Suisse Viti. Arbo. Hortic. 44, 192 (2012)

[4] D. Molitor, B. Augenstein, L. Mugnai, P.A. Rinaldi, J. Sofia, B. Hed, P.-H. Dubuis, M. Jermini, E. Kuehrer, G. Bleyer, L. Hoffmann, M. Beyer, Eur. J. Plant Pathol. 144, 785 (2016)

[5] W.K. Kast, Vitic. Enol. Sci. 51, 230

[6] P.-H. Dubuis, B. Bloesch, A.-L. Fabre, O. Viret, C. Mittaz, G. Bleyer, R. Krause, Rev. Suisse Viti. Arbo. Hortic. 46, 368 (2014)

[7] H.R. Schultz, Scientia Hortic. 52, 179 (1992)

[8] D. Molitor, J. Jünk, D. Evers, L. Hoffmann, M. Beyer, Am. J. Enol. Vitic. 65, 72 (2014)

[9] G. Bleyer, D. Molitor, P.-H. Dubuis, R. Krause, B. Augenstein, Der Deutsche Weinbau 14, 35 (2016)

[10] W. Siegfried, O. Viret, B. Hubert, R. Wohlhauser, Crop Prot. 26, 78 (2007)

[11] O. Viret, P.-H. Dubuis, B. Bloesch, A.-L. Fabre, D. Dupuis, Rev. Suisse Viti. Arbo. Hortic. 42, 226 (2010) 